\title{
Aplikasi Penyaringan Status dan Komentar di Facebook
}

\author{
Fradila Octa Kusuma W., Sarwosri, dan Ratih Nur Esti A. \\ Jurusan Teknik Informatika, Fakultas Teknologi Informasi, Institut Teknologi Sepuluh Nopember (ITS) \\ Jl. Arief Rahman Hakim, Surabaya 60111 Indonesia \\ e-mail: sri@cs.its.ac.id
}

\begin{abstract}
Abstrak-Kemudahan akses internet menyebabkan Facebook bisa diakses oleh hampir semua orang, bahkan anak-anak sekalipun. Sementara, tidak semua pengguna Facebook menyebarkan konten yang positif di dalam Facebook. Dengan semakin banyaknya konten negatif yang berkeliaran di Facebook, akan sangat membahayakan apabila anak-anak yang belum bisa membedakan mana yang baik dan buruk bertemu dengan konten negatif tersebut. Sehingga perlu adanya aplikasi yang mampu meminimalisir jumlah konten negatif yang mungkin dapat mengenai anak-anak. Berdasarkan sebab tersebut, dibuatlah suatu aplikasi yang mampu menyaring dan menyembunyikan status dan komentar yang dinilai negatif. Pengklasifikasian negatif dan tidaknya suatu status dan komentar dalam aplikasi ini menggunakan metode Naive bayes. Metode Naive bayes akan memecah status dan komentar menjadi kata-kata dan kemudian mencari probabilitas negatif dari status tersebut terhadap data latih yang telah dibuat sebelumnya. Aplikasi ini dibangun pada situs web tersendiri dan bukan di dalam Facebook. Pengujian fungsionalitas aplikasi dilakukan melalui skenario yang mencerminkan fitur aplikasi. Hasil pengujian fungsionalitas menunjukkan aplikasi dapat berjalan dengan cukup baik. Pada pengujian validitas, didapatkan precision sistem adalah $46,67 \%$ dan recall sistem adalah $93,33 \%$.
\end{abstract}

Kata Kunci-Facebook, Kalimat Negatif, Komentar, Naive bayes, Status.

\section{PENDAHULUAN}

$\mathrm{F}$ ACEBOOK merupakan salah satu media sosial paling populer di Indonesia. Kepopuleran tersebut ditandai dengan banyaknya pengguna dari segala kalangan dan umur. Keberagaman pengguna tersebut tentunya berdampak pula pada keberagaman konten yang ada di dalam Facebook, dan tentunya tidak semuanya positif.

Dengan kemungkinan banyaknya dampak negatif yang muncul di Facebook, akan sangat membahayakan apabila anak kecil yang memiliki akun Facebook menemui konten negatif ketika membuka Facebook. Karena itulah diperlukan sebuah aplikasi yang mampu menyaring konten negatif di dalam Facebook. Dengan penyaringan tersebut diharapkan dapat mengurangi konten negatif yang ada di dalam Facebook.

Aplikasi yang dibuat disini didasari oleh permasalahan tersebut. Penyaringan yang dilakukan berfokus pada pengklasifikasian status dan komentar di kronologi Facebook. Pengklasifikasian status dan komentar tersebut dilakukan dengan metode Bayes yang akan memberi nilai positif tidaknya status dan komentar. Kemudian menyembunyikan status dan komentar tersebut dengan cara mengganti karakter dalam status dan komentar dengan karakter '*'. Aplikasi ini dibangun pada situs web tersendiri, tidak tergabung dengan Facebook.

\section{TINJAUAN PUSTAKA}

\section{A. Penelitian Sebelumnya}

Pada penelitian sebelumnya yang menggunakan teori Bayes untuk menyaring percakapan pada situs jejaring sosial [1], penulis merujuk pada penggunaan teori Bayes. Untuk fitur aplikasi, penulis merujuk pada penelitian dimana dilakukan penyaringan dinding Facebook dengan menggunakan Machine Learning [2].

\section{B. Teori Bayes}

Teori Bayesian adalah teori yang menyediakan kerangka kerja matematis untuk menarik kesimpulan atau memberi alasan dengan menggunakan kemungkinan. Pada aplikasi ini, teori Bayes digunakan pada proses pemberian nilai negatif dari status dan komentar.

Apabila kemungkinan gabungan dari dua kejadian A dan B ditunjukkan pada persamaan (1) dan (2), pada teori Bayes salah satu kejadian tersebut adalah hipotesa $\mathrm{H}$, dengan diketahui data D, teori Bayes akan mencari kebenaran relatif dari hipotesa yang diberikan data sesuai dengan persamaan (3) [3].

$$
\begin{aligned}
P(A B) & =P(A \mid B) P(B) \\
& =P(B \mid A) P(A) \\
P(H \mid D) & =\frac{P(D \mid H) P(H)}{P(D)}
\end{aligned}
$$

\section{Facebook}

Facebook adalah jejaring sosial populer yang dibuat pertama kali pada tahun 2004 oleh Mark Zuckerberg dan kawan-kawan [4]. Salah satu bagian dari Facebook adalah timeline atau kronologi, yang memungkinkan pengiriman pesan antar teman di Facebook [5]. Status di dalam Facebook adalah fitur yang mengijinkan pengguna untuk memasang dan menyebarkan sedikir bagian dari profil pengguna agar dapat dilihat oleh pengguna Facebook yang lain. Komentar yang menyertai status Facebook adalah hasil dari pengamatan berupa opini maupun respon terhadap status Facebook [6]. Sejauh ini, proses penyaringan status dalam Facebook dilakukan secara manual oleh pengguna dengan cara menyeleksi nama pengguna lain 
yang tidak ingin ditampilkan dalam beranda, tidak mengikuti pengguna tertentu, maupun dengan menghilangkan status pengguna lain secara manual [7].

\section{Pengujian Validitas}

Pengujian vailiditas adalah pengujian untuk menemukan precision dan recall sistem. Pengujian dilakukan dengan cara menghitung jumlah true positive, true negative, false positive, dan false negative dari data yang diuji. Penghitungan precision sistem dan recall sistem dapat dilihat berturut-turut pada persamaan (4) dan (5) [8].

$$
\begin{aligned}
& \text { precision }=\frac{\sum \text { truepositive }}{\sum \text { kasusprediksi }} \\
& \text { recall }=\frac{\sum \text { truepositive }}{\sum \text { kasusnilaiyangdicari }}
\end{aligned}
$$

\section{METODOLOGI}

\section{A. Analisis Kebutuhan}

Aplikasi ini diharapkan mampu menyaring status dan komentar di dalam Facebook dengan disertai nilai dari status dan komentar tersebut. Dari latar belakang tersebut, dapat dipetakan kebutuhan fungsional dari sistem yaitu pengguna akan mendapatkan status dan komentar hasil dari penyaringan serta pengguna dapat mengelola data latih.

\section{B. Skenario Kasus Penggunaan}

Berdasarkan analisis kebutuhan di atas, didapatkan kasus penggunaan aplikasi sesuai pada Gambar 1.

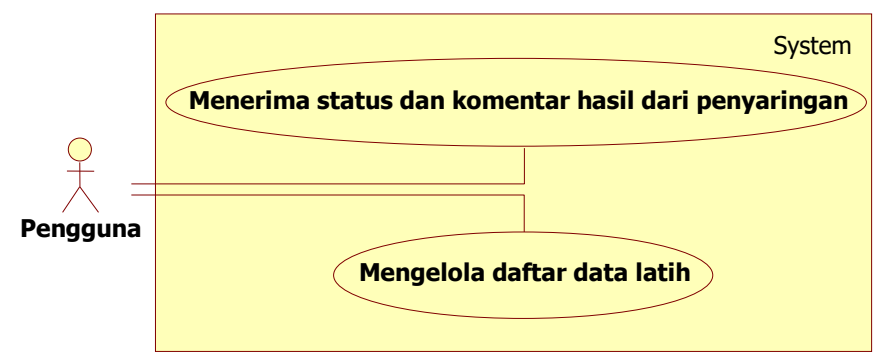

Gambar 1. Diagram kasus penggunaan aplikasi

Pada Gambar 1 dapat dilihat bahwa saat membuka aplikasi, pengguna akan menerima status dan komentar yang telah disaring oleh aplikasi. Selain itu pengguna juga dapat melakukan pengolahan terhadap data latih di dalam aplikasi. Pengolahan data yang dimaksud meliputi penambahan, penghapusan, dan pengubahan data.

\section{Implementasi Penyaringan Status dan Komentar}

Algoritma yang digunakan dalam implementasi penyaringan status dan komentar ini adalah Naive bayes. Secara singkat, cara kerja algoritma Naive bayes dalam proses penyaringan adalah sebagai berikut.

1. Mengambil string status lalu memisah string per kata.

2. Melakukan penghitungan untuk nilai negatif.

3. Menghitung jumlah data latih negatif, positif, dan total data latih.
4. Menghitung jumlah munculnya kata dalam data latih dan probabilitas masing-masing kata terhadap data latih.

5. Menggunakan metode Bayes untuk menghitung nilai kalimat berdasarkan probabilitas masing-masing kata.

6. Mengulangi perhitungan untuk nilai positif.

7. Mengambil nilai probabilitas paling besar sebagai nilai kalimat.

Implementasi dari penggunaan Naive bayes dalam aplikasi dapat dilihat pada Gambar 2.

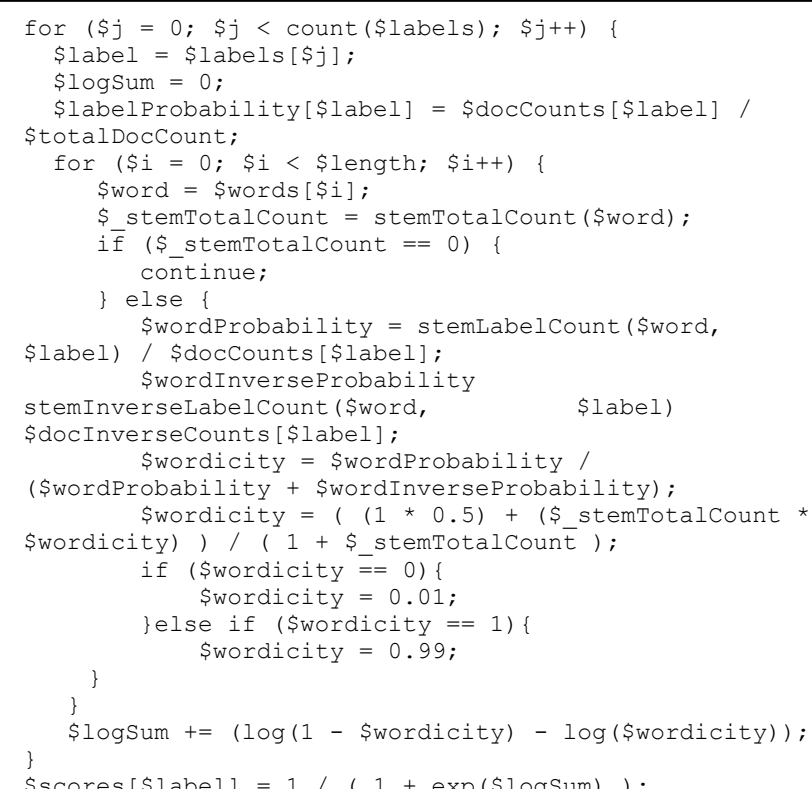

Gambar 2 Implementasi algoritma Naive bayes dalam proses penyaringan status dan komentar

Hasil dari implementasi proses penyaringan ini dapat dilihat pada Gambar 3.

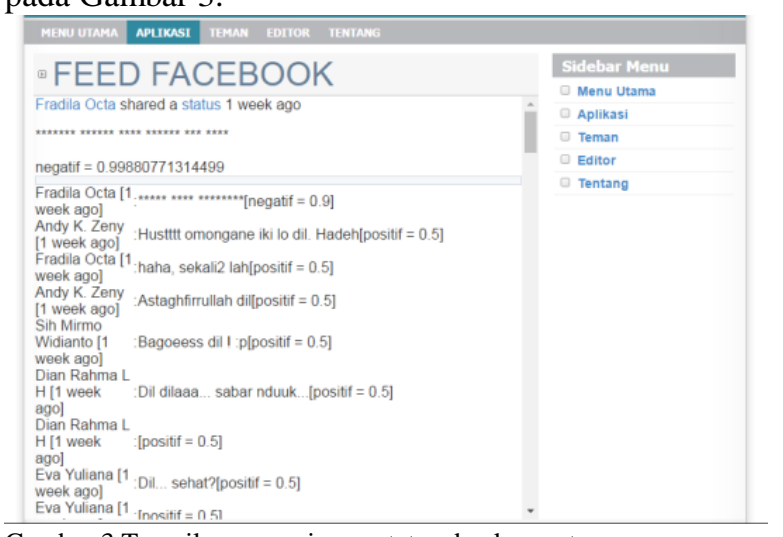

Gambar 3 Tampilan penyaringan status dan komentar.

\section{PENGUJIAN}

Pengujian aplikasi dilakukan dengan menggunakan sebuah laptop dengan prosesor Intel(R) Core $^{\mathrm{TM}}$ i3 CPU M370 $@ 2,40 \mathrm{GHz}, \mathrm{RAM} 4,00 \mathrm{~GB}$, dan sistem operasi Windows 7 Ultimate (64bit). Ada dua macam pengujian yang dilakukan pada aplikasi, yaitu pengujian fungsional dan pengujian validitas. 


\section{A. Pengujian Fungsionalitas}

Pengujian ini dilakukan untuk mengetahui fungsionalitas aplikasi yang diidentifikasi pada tahap kebutuhan telah berjalan sesuai harapan dan berjalan semestinya. Pengujian ini dilakukan dengan metode black-box.

Fungsionalitas yang diuji adalah fungsionalitas menampilkan status dan komentar hasil dari penyaringan serta fungsionalitas mengolah data. Salah satu hasil pengujian ini dapat dilihat pada Gambar 4.

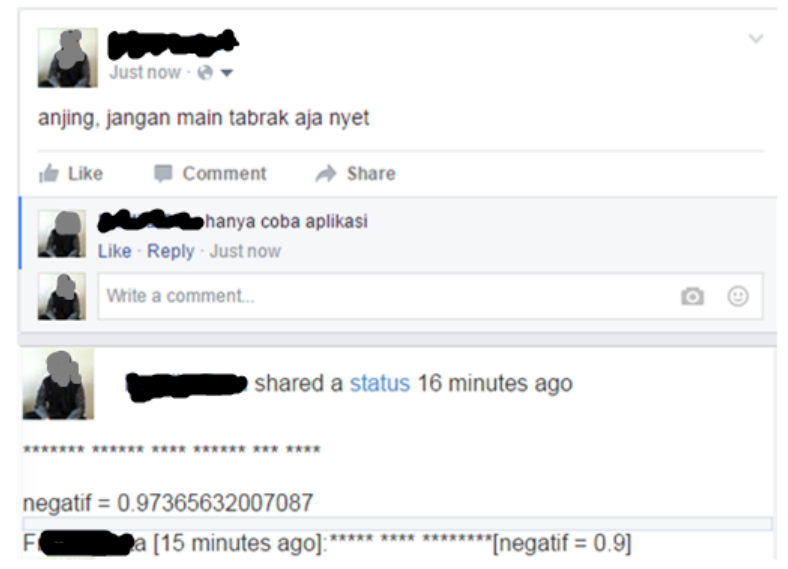

Gambar 4 Tampilan hasil penyaringan status dan komentar

Hasil pengujian terhadap fungsionalitas menampilkan status dan komentar menunjukkan bahwa fitur tersebut berjalan dengan baik. Sedangkan pengujian untuk fungsionalitas mengelola data latih juga memberikan hasil bahwa fungsionalitas tersebut dapat berjalan dengan semestinya.

\section{B. Pengujian Validitas}

Pengujian validitas akan mencari precision dan recall dari sistem berdasarkan data uji yang telah dipilih. Beberapa data uji dapat dilihat pada Tabel 1. Sebelum dilakukan penghitungan precision dan recall diperlukan penghitungan true positive, true negative, false positive, dan false negative dari data uji. Hasil dari pengujian ini adalah precision sistem $46,67 \%$ dan recall sistem adalah $93,33 \%$.

\section{KESIMPULAN DAN SARAN}

Dari hasil pengujian yang telah dilakukan terhadap aplikasi, dapat diambil kesimpulan sebagai berikut.

1. Kebutuhan fungsional aplikasi dapat berjalan dengan semestinya.

2. Aplikasi ini memiliki nilai precision mendekati $50 \%$ dan recall mendekati $100 \%$.

Saran untuk pengembangan aplikasi selanjutnya adalah agar aplikasi dapat dikembangkan di platform Facebook, diperlukannya penambahan data latih, dan juga perlunya studi lebih lanjut mengenai pemberian nilai negatif suatu kalimat.

Tabel 1.

Beberapa data uji validitas

\begin{tabular}{c|l|c|c}
\hline \hline No & \multicolumn{1}{|c|}{ Kalimat } & Nilai Asli & Nilai Uji \\
\hline 1 & Cewek kampungan, rumahmu pasti & Negatif & Positif \\
& bau busuk & 0,625 \\
2 & Pejabat itu punya istri simpanan yang & Negatif & Negatif
\end{tabular}

\begin{tabular}{c|l|c|c} 
& sedang bunting & & 0,927 \\
3 & Anjingmu lucu banget & Positif & Positif \\
& & & 0,964 \\
4 & Kalau sudah busuk mending jangan & Positif & Positif \\
& dimakan & & 0,988 \\
\hline \hline
\end{tabular}

\section{DAFTAR PUSTAKA}

[1] Arpit Trivedi Shreya Mahida, "Evaluation of Social Networking Site Conversation Filtering Based on Bayesian Theory," International Journal of Advanced Research in Computer Science and Software Engineering, vol. 3, no. 11, pp. 163-165, November 2013.

[2] E. Binaghi, B. Carminati, M. Carullo, E. Ferrari M. Vanetti, "Contentbased Filtering in On-line Social Networks," University of Insubria, Varese, paper.

[3] Bruno A. Olshausen. (2004, March) Bayesian Probability Theory. [Online]. http://redwood.berkeley.edu/bruno/npb163/bayes.pdf.

[4] Jonathan Strickland. (2007, December) How Stuff Works.[Online]. http://computer.howstuffworks.com/internet/socialnetworking/networks/facebook.htm.

[5] Stacey Harmon. (2015, February) Harmon Enterprises Blog. [Online]. http://www.harmonenterprises.com/blog/coaching/facebooks-wall-vsnews-feed-explained.

[6] Ebta Setiawan. (2012) Kamus Besar Bahasa Indonesia. [Online]. http://kbbi.web.id/.

[7] Facebook. (2016) Facebook Help Centre. [Online]. https://www.facebook.com/help/335291769884272/.

[8] Tilmann Bruckhaus. KD Nuggets : Data Mining, Analytics, Big Data, and Data Science. [Online]. http://www.kdnuggets.com/faq/precisionrecall.html. 